\title{
Volatile Aroma Compounds in Jasmine Rice as Affected by Degrees of Milling
}

\author{
Issaraporn JINAKOT ${ }^{1}$ and Wannee JIRAPAKKUL ${ }^{1,2, *}$ \\ ${ }^{1}$ Department of Food Science and Technology, Faculty of Agro-Industry, \\ Kasetsart University, Bangkok, Thailand \\ ${ }^{2}$ Center of Advanced Studies for Agriculture and Food (CASAF), Kasetsart University Institute for \\ Advanced Studies, Kasetsart University, Bangkok, Thailand
}

\begin{abstract}
Summary Jasmine rice (Khao Dawk Mali 105) is popular because of its pleasant unique aroma. Milling is an important step in order to produce various types of edible rice. The distribution of volatile aroma compounds in rice especially, endosperm and bran fractions are different. Hence, the purpose of this study was to determine the volatile aroma compounds of low-milled and high-milled Jasmine rice that affect the aroma quality of cooked rice. The new crop of Jasmine paddy was used in this study. Volatile aroma compounds in raw and cooked rice with two degrees of milling, i.e., low-milled rice ( $2-4 \%$ rice bran) and high-milled rice (11-13\% rice bran) were investigated. The raw and cooked samples were extracted with dichloromethane and analyzed by gas chromatography-time of flight mass spectrophotometer (GC-TOFMS). The amount of volatile aroma compounds in rice was decreased with high milling. 3-Penten-2-ol (green odor), the most abundant compound in raw rice, was the lowest amount in high-milled rice. On the other hand, the high-milled rice bran had the highest amount of this compound. After cooking, more types of volatile aroma compounds were detected. 2-Acetyl-1-pyrroline (2AP) (pandan-like, popcorn-like) was the most abundant in cooked rice. Meanwhile, hexanal was the highest amount in cooked rice bran. However, 2AP was the potent aroma compound with the highest odor activity values in both raw and cooked rice with low and high milling degree as well as in rice bran.
\end{abstract}

Key Words Jasmine rice, rice bran, degrees of milling, 2-Acetyl-1-pyrroline

Jasmine rice or Khao Dawk Mali 105 (KDML 105) is the most important aromatic long grain rice variety in Thailand. KDML 105 can produce the aroma during cooking, as well as growing in the fields. The volatile compounds in aromatic rice have been identified more than 200 compounds. 2-Acetyl-1-pyrroline (2AP), a popcorn-like or pandan-like aroma compound was the important aroma compound in cooked aromatic rice (1). After harvest, paddy is dehulled in order to get brown rice. Milling is one of the important steps of rice process to produce various types of rice grain. As the degree of milling increased, the partial surface of rice bran and endosperm are removed. The different degree of milled rice has the different chemical compounds. Moreover, milling level has affected to overall aroma in cooked short grain rice and its sensory evaluation (2).

Lipids and proteins are predominantly found in rice bran (3). The rice bran which is the by-product from milling also has the aroma characteristic. The residual from rice bran in milled rice can also affect the aroma in cooked rice (4).

The distribution of rice bran layer and partial endosperm which affect to overall aroma in KDML 105 has not been assessed. Therefore, the objectives of this study were to identify and compare the volatile aroma com-

\footnotetext{
*Corresponding author.
}

E-mail: wannee.ch@ku.th pounds in milled rice and rice bran at different degrees of milling.

\section{Matherials and Methods}

Materials. Khao Dawk Mali 105 (KDML105) paddy, harvested in year 2018 was obtained from Agricultural Marketing Co-Operative in the northeastern region of Thailand.

Sample preparation. Paddy was dehulled using rubber rolls to obtain brown rice. The brown rice was milled using horizontal abrasive whitening machine with 2 levels of milling; low-milled (2-4\% of removed rice bran) and high-milled (11-13\% of removed rice bran) (4).

Moisture content. The moisture content of rice and rice bran was analyzed using hot air oven $130 \pm 3^{\circ} \mathrm{C}$ for 1 h until stable weight (5).

Heat treatment of raw milled rice and rice bran. The amount of $50 \mathrm{~g}$ of low-milled and high-milled rice was added with deodorized water at the ratio of $1: 1.5$ and $1: 1.2$, respectively, and steamed in rice cooker for $40 \mathrm{~min}$. For rice bran, each $30 \mathrm{~g}$ of low-milled and high-milled degree was added with deodorized water at the same ratio as rice.

Extraction of volatile compounds. The rice sample was immersed with liquid nitrogen before grinding. 50 and $30 \mathrm{~g}$ of grinded rice and rice bran was spiked with 25 and $15 \mu \mathrm{L}$ of 2 -methyl-3-heptanone $(1.18 \mathrm{mg} / 10 \mathrm{~mL}$ in methanol) as internal standard and extracted with 


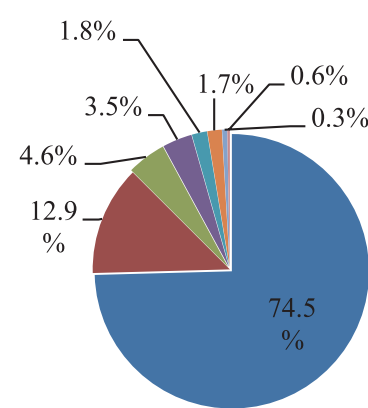

(A)

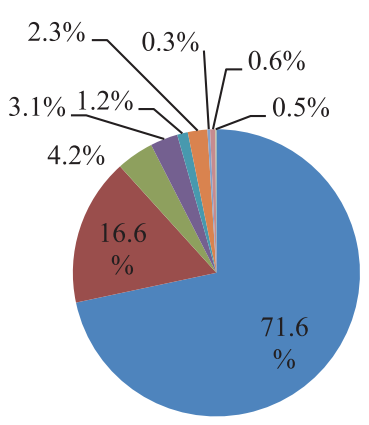

(B)

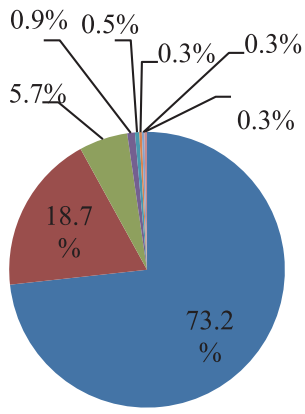

(C)

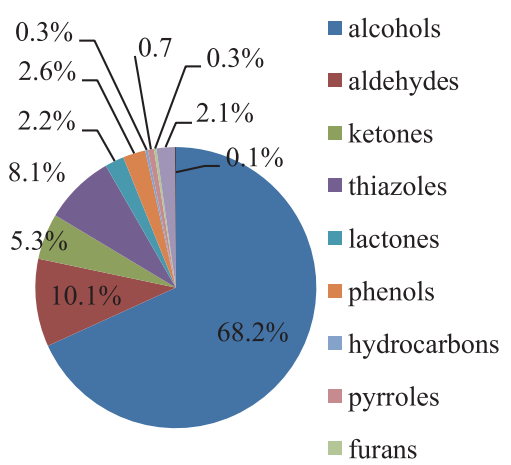

(D)

acids

High-milled degree

Fig. 1. Relative concentration (\%) of volatile aroma groups in low- milled rice (A) and rice bran (B) and high-milled rice (C) and rice bran (D) (raw).

Table 1. Relative concentration of selected volatile aroma compounds with the most abundant/the highest OAVs in lowmilled and high-milled rice and rice bran.

\begin{tabular}{|c|c|c|c|c|c|c|c|c|c|c|}
\hline \multirow{3}{*}{$\begin{array}{l}\text { Volatile } \\
\text { compounds }\end{array}$} & \multirow{3}{*}{$\begin{array}{c}\text { Odor } \\
\text { description* }\end{array}$} & \multirow{3}{*}{ RI } & \multicolumn{8}{|c|}{ Relative concentration (ng/g) } \\
\hline & & & \multicolumn{4}{|c|}{ Low-milled degree } & \multicolumn{4}{|c|}{ High-milled degree } \\
\hline & & & $\mathrm{RR}$ & $\mathrm{RRB}$ & $\mathrm{CR}$ & $\mathrm{CRB}$ & $\mathrm{RR}$ & $\mathrm{RRB}$ & $\mathrm{CR}$ & $\mathrm{CRB}$ \\
\hline hexanal & green & $<1100$ & $50.8^{\mathrm{a}, \mathrm{B}}$ & $155.6^{\mathrm{b}, \mathrm{A}}$ & $45.8^{\mathrm{a}, \mathrm{B}}$ & $392.1^{\mathrm{b}, \mathrm{A}}$ & $44.6^{\mathrm{b}, \mathrm{B}}$ & $304.3^{\mathrm{a}, \mathrm{A}}$ & $52.1^{\mathrm{b}, \mathrm{B}}$ & $819.2^{\mathrm{a}, \mathrm{A}}$ \\
\hline 3-penten-2-ol & green & 1188 & $421.2^{\mathrm{a}, \mathrm{A}}$ & $1,406.3^{\mathrm{b}, \mathrm{A}}$ & $59.3^{\mathrm{a} . \mathrm{A}}$ & $143.6^{\mathrm{b}, \mathrm{A}}$ & $243.3^{\mathrm{b}, \mathrm{A}}$ & $4,632.7^{\mathrm{a}, \mathrm{A}}$ & $36.9^{\mathrm{b}, \mathrm{A}}$ & $116.1^{\mathrm{a}, \mathrm{A}}$ \\
\hline heptanal & green, fruity & 1194 & n.d. & $5.2^{\mathrm{b}}$ & $1.6^{\mathrm{a}, \mathrm{B}}$ & $34.1^{\mathrm{b}, \mathrm{A}}$ & n.d. & $13.0^{\mathrm{a}}$ & $1.7^{\mathrm{a}, \mathrm{B}}$ & $70.3^{\mathrm{a}, \mathrm{A}}$ \\
\hline octanal & green, fruity & 1307 & $2.8^{\mathrm{a}, \mathrm{B}}$ & $6.2^{\mathrm{b}, \mathrm{A}}$ & $3.4^{\mathrm{a}, \mathrm{B}}$ & $48.1^{\mathrm{b}, \mathrm{A}}$ & $0.2^{\mathrm{a}, \mathrm{A}}$ & $40.7^{\mathrm{a}, \mathrm{A}}$ & $3.5^{\mathrm{a}, \mathrm{B}}$ & $138.2^{\mathrm{a}, \mathrm{A}}$ \\
\hline $\begin{array}{l}\text { 2-acetyl-1- } \\
\text { pyrroline }\end{array}$ & $\begin{array}{l}\text { popcorn-like, } \\
\text { pandan-like }\end{array}$ & 1344 & $1.5^{\mathrm{a}, \mathrm{B}}$ & $13.0^{\mathrm{b}, \mathrm{A}}$ & $287.2^{\mathrm{a}, \mathrm{A}}$ & $94.2^{\mathrm{b}, \mathrm{B}}$ & $1.1^{\mathrm{a}, \mathrm{B}}$ & $53.9^{\mathrm{a}, \mathrm{A}}$ & $206.5^{\mathrm{b}, \mathrm{A}}$ & $140.7^{\mathrm{a}, \mathrm{B}}$ \\
\hline nonanal & green, soapy & 1395 & $21.4^{\mathrm{a}, \mathrm{B}}$ & $96.6^{\mathrm{b}, \mathrm{A}}$ & $42.8^{\mathrm{a}, \mathrm{B}}$ & $185.7^{\mathrm{b}, \mathrm{A}}$ & $17.7^{\mathrm{b}, \mathrm{B}}$ & $166.8^{\mathrm{a}, \mathrm{A}}$ & $45.5^{\mathrm{a}, \mathrm{B}}$ & $225.2^{\mathrm{a}, \mathrm{A}}$ \\
\hline cis-linalool oxide & sweet, floral & 1423 & n.d. & $2.7^{\mathrm{b}}$ & n.d. & $7.3^{\mathrm{b}}$ & n.d. & $15.7^{\mathrm{a}}$ & n.d. & $8.9^{\mathrm{a}}$ \\
\hline$\gamma$-butyrolactone & sweet, coconut & 1642 & $4.3^{\mathrm{a}, \mathrm{B}}$ & $13.1^{\mathrm{b}, \mathrm{A}}$ & $8.1^{\mathrm{a}, \mathrm{B}}$ & $26.9^{\mathrm{b}, \mathrm{A}}$ & $0.6^{\mathrm{a}, \mathrm{B}}$ & $68.4^{\mathrm{a}, \mathrm{A}}$ & $8.2^{\mathrm{a}, \mathrm{B}}$ & $66.8^{\mathrm{a}, \mathrm{A}}$ \\
\hline 2-acetylthiazole & roasty, nutty & 1653 & n.d. & n.d. & n.d. & $29.4^{\mathrm{b}}$ & n.d. & n.d. & n.d. & $49.4^{\mathrm{a}}$ \\
\hline $2(5 \mathrm{H})$-furanone & sweet, burnt & 1774 & n.d. & n.d. & $6.6^{\mathrm{a}, \mathrm{A}}$ & $25.4^{\mathrm{b}, \mathrm{A}}$ & n.d. & n.d. & $4.0^{\mathrm{a}, \mathrm{A}}$ & $54.4^{\mathrm{a}, \mathrm{A}}$ \\
\hline hexanoic acid & sweaty & 1864 & n.d. & n.d. & n.d. & $18.8^{\mathrm{b}}$ & n.d. & 130.9 & n.d. & $156.8^{\mathrm{a}}$ \\
\hline
\end{tabular}

* odor description (12).

n.d.: not detected.

$\mathrm{a}-\mathrm{b}$ with different letter was significantly different in degrees of milling comparison.

A-B with different letter was significantly different in rice and rice bran within the same degree of milling.

$\mathrm{RR}=$ raw rice, $\mathrm{RRB}=$ raw rice bran, $\mathrm{CR}=$ cooked rice and $\mathrm{CRB}=$ cooked rice bran .

dichloromethane at ambient temperature for $1 \mathrm{~h}$, equipped with high speed shaker. Extraction was carried out 3 times. The extract was concentrated using Vigreux column and further purified with high-vacuum distillation (under $10^{-5}$ torr). Then, the extract was dried with anhydrous $\mathrm{Na}_{2} \mathrm{SO}_{4}$. It was concentrated to $250 \mu \mathrm{L}$ and kept at $-80^{\circ} \mathrm{C}$ in amber vial until analysis.

Analysis of volatile compounds by gas chromatographytime of flight mass spectrometer (GC-TOFMS). Before analysis by using GC (7890A; Agilent Technologies; California, USA) coupled with TOFMS (Pegasus 4D; LECO $^{\circledR}$; Michigan, USA), the extract was concentrated to $200 \mu \mathrm{L}$. Volatile compounds were analyzed by cool on-column technique with oven tracking mode. The $1 \mu \mathrm{L}$ of extract was injected. The volatile compounds were analyzed on polar capillary column (Stabilwax ${ }^{\mathbb{B}}$;
$30 \mathrm{~m} \times 0.25 \mathrm{~mm}$ i.d. $\times 0.25 \mu \mathrm{m}$ film thickness; Restek; Pennsylvania, USA). The GC oven temperature was programmed as following: initial temperature of $35^{\circ} \mathrm{C}$ held for $5 \mathrm{~min}$, raised at a rate of $4^{\circ} \mathrm{C} / \mathrm{min}$ to $225^{\circ} \mathrm{C}$, and then held at this temperature for $15 \mathrm{~min}$. The carrier gas was helium at a constant flow rate of $1 \mathrm{~mL} / \mathrm{min}$.

Identification and quantification of volatile aroma compounds. The identification was based on comparison of retention index (RI). The RI was determined for each volatile compound against $n$-alkane reference standards (C6-C30), then matched with literatures on the same polar column and mass spectra of each volatile compound against NIST 02 mass spectral libraries. The relative concentration was reported as ng/g (ppb). Odor activity values $(\mathrm{OAVs})$ of identified compound was calculated as the ratio between the concentration and the 


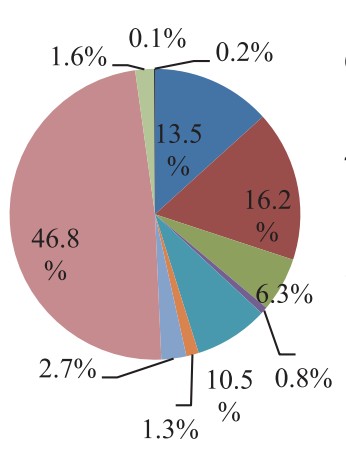

(A)

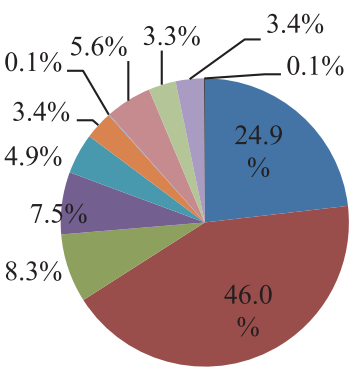

(B)

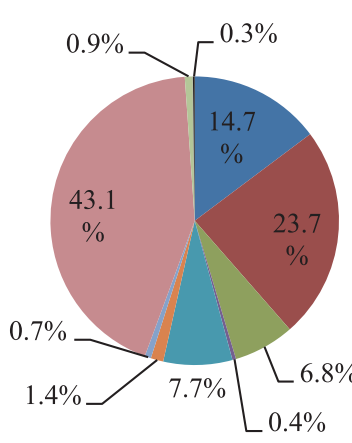

(C)

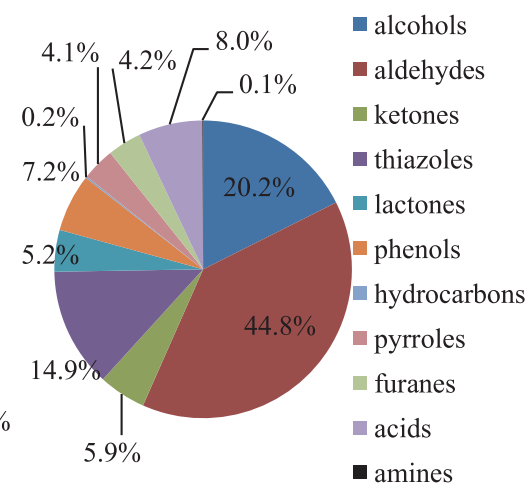

(D)

Low-milled degree

High-milled degree

Fig. 2. Relative concentration (\%) of volatile aroma groups in low- milled rice (A) and rice bran (B) and high-milled rice (C) and rice bran (D) (cooked).

odor threshold in air from the literatures.

Statistical analysis. The study was performed triplicate. Completely randomized design (CRD) was used. Pair sample $t$-test was conducted $(p<0.05)$. Statistical analysis was performed using SPSS v.17 (SPSS Inc., USA).

\section{Results}

Effect of degrees of milling on volatile aroma compounds in raw rice and rice bran

The amount of volatile aroma compounds in raw rice bran was higher than in milled rice for both low and high milling. Alcohols, aldehydes, ketones and thiazoles were predominant groups of identified compounds in low-milled and high-milled rice as well as rice bran (Fig. 1). Alcohols had the highest percentage of volatile aroma compounds. Among all the alcohols, 3-penten2-ol (green odor) was the largest amount. The second major group was aldehydes. In aromatic rice, most of aldehydes provided undesirable aroma with green aroma. Hexanal was the highest content. 2AP, the key aroma compound of Jasmine rice, was found in both rice and rice bran. In addition, cis-linalool oxide and hexanoic acid were found in rice bran. They are responsible for floral and sweaty notes, respectively.

The OAV was used to identify the potent aroma compounds $(\mathrm{OAVs}>1)$ which might contribute to the overall aroma of food. $2 \mathrm{AP}$ was the aroma compound with the highest OAVs in both milled rice and rice bran $(\mathrm{OAVs}=75$ and 650 in low-milled rice and rice bran and $\mathrm{OAVs}=55$ and 2,695 in high-milled rice and rice bran). Effect of heat treatment on volatile aroma compounds in rice and rice bran

The heat treatment from steam-cooking increased the concentrations of volatile aroma compounds (Table 1 ). For both degrees of milling, the amount of volatile aroma compounds in rice bran was higher than those of rice. Pyrrole was the major group of aroma compounds in rice. $2 \mathrm{AP}$ was the largest amount in cooked rice. Meanwhile, aldehydes were the predominant group and hexanal was the most abundant in rice bran (Fig. 2 ). For lactones, oxidation product by heat inducing, might partly contribute to the sweet and coconut-like odor. Some furanes such as furfural and 2(5H)-furanone were detected due to heat generation. Hexanoic acid and 2-acetythiazole were found only in rice bran. In addition, 2AP was the major potent aroma compound with the highest OAVs in both rice and rice bran after heat treatment. $(\mathrm{OAVs}=14,360$ and 4,710 in low-milled and $\mathrm{OAVs}=10,325$ and 7,035 in high-milled rice and rice bran).

\section{Discussion}

The amount of volatile aroma compounds in rice bran was higher than in milled rice. Furthermore, the volatile compounds in high-milled rice bran were higher due to more chemical composition in bran $(3,4)$. The presence of 3-penten-2-ol might be the product from degradation of lipid and carbohydrate (6). Moreover, the alcohols, methyl ketones, aldehydes and lactones could result from fatty acid (7) which reported in rice and rice bran (8). Some furanes were the product of amino acid and reducing sugar via Maillard reaction, including 2-acethylthiazole (9). Furthermore, cis-linalool oxide was generated by the glycoside of linalool oxides. The glycation bond might be cleaved by $\beta$-D-glucosidase which found in rice bran (10). In addition, hexanoic acid was the product from oxidation of hexanal in aromatic rice (11). 2AP was found in both rice and rice bran. 2AP in raw rice was higher than in rice bran. Meanwhile, $2 \mathrm{AP}$ in rice bran was lower after steam-cooking. This might due to aroma release from bran in powder form by heat treatment. Therefore, $2 \mathrm{AP}$ in bran was more heat sensitive than in rice. Furthermore, cis-linalool oxide, 2acetylthiazole and hexanoic acid (Table 1) were detected in rice bran.

This indicated that these volatile aroma compounds seemed to be in bran and outer layer of endosperm fraction. 


\section{Conclusion}

2-Acetyl-1-pyrroline was the most potent aroma compound with the highest OAV in both raw and cooked rice at low and high degree of milling as well as in rice bran. On the other hand, hexanal, undesirable aroma in aromatic rice, was the second potent aroma compound in high-milled rice bran. Therefore, the degrees of milling would play an important role in the aroma quality of the aromatic rice due to the residual volatile aroma compound in rice bran.

\section{Disclosure of State of COI}

No conflicts of interest to be declared.

\section{Acknowledgments}

This research was supported from graduate scholarship provided by the National Research Council of Thailand (NRCT) as of fiscal year 2018.

\section{REFERENCES}

1) Paule CM, Powers JJ. 1989.Sensory and chemical examination of aromatic and nonaromatic rices. J Food Sci 54: 343-346.

2) Tsugita T, Kurata T, Kato H. 1980. Volatile components after cooking rice milled to different degrees. Agric Biol Chem 44: 835-840.

3) Zhou Z, Robards K, Helliwell S, Blanchard C. 2002. Composition and functional properties of rice. Int J Food Sci Technol 37: 849-868.

4) Lamberts L, Bie DL, Vandeputte EG, Veraverbeke SW, Derycke V, Man DW, Delcour AJ. 2007. Effect of milling on colour and nutritional properties of rice. Food Chem
100: $1496-1503$.

5) Horwitz W. 2000. Official Methods of Analysis. In: AOAC International (Horwitz W, ed), Vol 17. Gaithersburg, MD, USA.

6) Cho IH, Choi HK, Kim YS. 2006. Difference in the volatile composition of pine-mushrooms (Tricholoma matsut matsutake Sing.) according to their grades. J Agric Food Chem 54: 4820-4825.

7) Litman I, Numrych S. 1978.The role lipids play in the positive and negative flavors of food. In: Lipids as a Source of Flavor (Supran MK, ed), Vol 45, p 1-17. American Chemical Society, Washington DC.

8) Champagne ET, Wood D, Juliano BO, Bechtel DB. 2004. Chapter 4: The rice grain and its gross composition. In: Rice: Chemistry and Technology (Champagne ET, ed), p 77-107. American Association of Cereal Chemists Press, Minneapolis, MN.

9) Yanagimoto K, Lee GK, Ochi H. Shibamoto T. 2002. Antioxidative activity of heterocyclic compounds found in coffee volatiles produced by Maillard reaction. J Agric Food Chem 54: 4820-4825.

10) Harada K M, Tanaka K, Fukuda Y, Hashimoto W, Murata K. 2005. Degradation of rice bran hemicellulose by Paenibacillus spp. strain HC1: gene cloning, characterization and function of $\beta$-D-glucosidase as an enzyme involved in degradation. Arch Microbiol 184: 215-221.

11) Lee K G, Mitchell A, Shibamoto T. 2000. Antioxidative activities of aroma extracts isolated from natural plants. Biofactors 13: 173-178.

12) Leffingwell CJ. 2004. GRAS \& EC Flavor Chemicals Report. Flavor Base Professional Software Version 2004. Serial Number: FLAVBASE2004; Copyright 19892004. Canton, GA, USA. 